\title{
Smeared crack modelling approach for corrosion-induced concrete damage
}

\author{
Thybo, Anna Emilie Anusha; Michel, Alexander; Stang, Henrik
}

Published in:

Materials and Structures

Link to article, DOI:

10.1617/s11527-017-0999-5

Publication date:

2017

Document Version

Peer reviewed version

Link back to DTU Orbit

\section{Citation (APA):}

Thybo, A. E. A., Michel, A., \& Stang, H. (2017). Smeared crack modelling approach for corrosion-induced concrete damage. Materials and Structures, 50(146). https://doi.org/10.1617/s11527-017-0999-5

\section{General rights}

Copyright and moral rights for the publications made accessible in the public portal are retained by the authors and/or other copyright owners and it is a condition of accessing publications that users recognise and abide by the legal requirements associated with these rights.

- Users may download and print one copy of any publication from the public portal for the purpose of private study or research.

- You may not further distribute the material or use it for any profit-making activity or commercial gain

- You may freely distribute the URL identifying the publication in the public portal 


\title{
Smeared Crack Modelling Approach for Corrosion- induced Concrete Damage
}

\author{
Anna Emilie A. Thybo \\ Alexander Michel \\ Henrik Stang \\ Department of Civil Engineering \\ Technical University of Denmark \\ Brovej, Building 118 \\ 2800 Kgs. Lyngby \\ Denmark \\ Phone: +45 23679969 \\ Fax: +45 45883282 \\ aeth@byg.dtu.dk \\ www.byg.dtu.dk
}


In this paper a smeared crack modelling approach is used to simulate corrosion-induced damage in reinforced concrete. The presented modelling approach utilizes a thermal analogy to mimic the expansive nature of solid corrosion products, while taking into account the penetration of corrosion products into the surrounding concrete, non-uniform precipitation of corrosion products, and creep. To demonstrate the applicability of the presented modelling approach, numerical predictions in terms of corrosion-induced deformations as well as formation and propagation of micro- and macrocracks were compared to experimental data obtained by digital image correlation and published in the literature. Excellent agreements between experimentally observed and numerically predicted crack patterns at the micro and macro scale indicate the capability of the modelling approach to accurately capture corrosion-induced damage phenomena in reinforced concrete. Moreover, good agreements were also found between experimental and numerical data for corrosion-induced deformations along the circumference of the reinforcement.

Keywords: Concrete cracking, Smeared crack modelling approach, FEM, Corrosion 


\section{Introduction}

Along with globalisation, increase in population, and streamlining of transportation the demand for new infrastructures and, in general, the demand for sustainability of structures is expanding and, thereby, having a great effect on socio-economics. Understanding of structural performance as well as material behaviour is, therefore, of great importance and research within these fields has grown during the last decades (Andrade et al. 1993; Cabrera 1996; Molina et al. 1993; Alonso et al. 1998; Noghabai 1999; Solgaard et al. 2013; Michel et al. 2013).

A leading deterioration mechanism, in reinforced concrete structures, is corrosion (Rendell et al. 2002), which may cause debonding/delamination in the concrete/reinforcement interface, cracking in cover layer, and decrease in durability due to corrosion of steel. Several studies have focused on modelling corrosion-induced damage leading to a variety of modelling approaches, e.g. finite element (FE) based (Biondini and Vergani 2012; Solgaard 2013) and analytical (Bazant 1979; Liu and Weyers 1998; Chernin et al. 2010; Bohner E. 2010). Recent studies (Pease et al. 2012; Michel et al. 2013) have shown that corrosion products precipitate non-uniformly (even under accelerated conditions applying direct current) and penetrate into the surrounding concrete, which may have an influence on state-of-the-art FE modelling approaches dealing with corrosion-induced concrete damage.

Within this paper a FE modelling approach based on a discrete crack modelling that includes the penetration of corrosion products into the surrounding concrete (Michel et al. 2013) is further developed. The development includes the formulation of corrosion-induced concrete damage within a smeared crack modelling approach, which takes into account the penetration of corrosion products into the available pore space surrounding the reinforcement, non-uniform precipitation of corrosion products, and creep. The developed smeared crack modelling approach was then used to investigate the influence of the penetration of corrosion products into the surrounding concrete and the elastic modulus of corrosion products on corrosion-induced concrete damage. Finally, numerical results of the smeared crack modelling approach, i.e. modelled crack patterns, deformations near the concrete/reinforcement interface, and surface crack width, were compared to experimental observations obtained from accelerated corrosion experiments and data provided in the literature.

\section{Introduction to corrosion-induced crack modelling}

Once corrosion is initiated, electrochemical half-cell reactions are taking place along the reinforcement surface. The ionic reaction products of those half-cell reactions may further react and form solid corrosion products in the vicinity of the reinforcement. The type of corrosion products formed depends on the thermodynamic conditions present in the vicinity of the reinforcement (Küter et al. 2008). Apart from solid corrosion products, soluble iron-chloride complexes (also referred to as green rust) may form in an oxygen-deprived environment in which chlorides are present (Küter et al. 2008; Koleva et al. 2006). Such soluble iron-chloride complexes may not necessarily form in the vicinity of the reinforcement surface, as shown e.g. in Küter et al. (2008). However, independent of the type of iron oxides formed as a result of active corrosion, iron oxides occupy a larger volume than the initial iron that is consumed during the corrosion reaction; see e.g. Alonso et al. (1998). The increased volume of corrosion products causes tensile stresses in the 
surrounding concrete and may lead to concrete cracking, spalling, or delamination, if the tensile capacity of the concrete is exceeded.

To model the expansive nature of corrosion products, a thermal analogy may be used as shown in Fig. 1. To mimic the increased volume of corrosion products, a 'fictitious' thermal load is applied to the corroded reinforcement section. Basic geometrical considerations and finite element method load application are illustrated in Fig. 1. The thickness of the corroded reinforcement section, $X(t)$, may be determined using Faraday's law, which describes the reduction in reinforcement radius due to corrosion:

$X(t)=\frac{M i_{c o r r} \Delta t}{z F \rho}$

$M$ is the molar mass of the metal $[\mathrm{g} / \mathrm{mol}], i_{\text {corr }}$ the corrosion current density $\left[\mathrm{A} / \mathrm{mm}^{2}\right], \Delta t$ the duration of current application [s], $z$ the anodic reaction valence [-], $F$ Faraday's constant [96485 As $/ \mathrm{mol}]$ and $\rho$ the density of the metal $\left[\mathrm{g} / \mathrm{mm}^{3}\right]$.

The thickness of the free expanding corrosion products can be expressed as (see e.g. Fig. 5):

$\Delta R_{0}=R_{2}-R_{0}$

Based on this, a 'fictitious' thermal load is applied to the corroded reinforcement section accounting for the expansion of corrosion products:

$\Delta R_{0}=X(t) \eta_{\text {lin }}=\left(R_{0}-R_{1}\right) \eta_{\text {lin }}$

where $\eta_{\text {lin }}$ is the linear expansion coefficient [-] depending on the type of corrosion products formed and described by a 'fictitious' thermal expansion coefficient, $\alpha\left[\mathrm{K}^{-1}\right]$, and a corresponding temperature increment, $\Delta T[\mathrm{~K}]$. Assuming a constant coefficient of thermal expansion, $\alpha$, the applied temperature increment, $\Delta T$, represents then the type of solid corrosion product. Assuming further isotropic material properties of the corrosion products, the linear expansion coefficient may be obtained as one third of the volume expansion coefficient:

$\eta_{\text {lin }}=\alpha \Delta T$

\section{Discrete Crack Modelling Approach}

The foundation for the smeared crack modelling approach developed in this study is a FE based modelling approach in which corrosion-induced concrete damage is simulated by means of a discrete crack modelling approach (Michel et al. 2010; Solgaard 2013; Pease et al. 2012; Michel et al. 2013).

In general, five distinct regions (concrete, reinforcement, corrosion layer, and a cracking and debonding domain) form the modelled system, which simulates corrosion-induced cracking. In the model, uniform corrosion was assumed along the length and along the circumference of the reinforcement, for which a 2D plain strain formulation may be used. Cracking of the cementitious matrix was considered along a predefined crack path including delamination at the concrete/reinforcement interface, the former was modelled according to mode-I fracture and the latter was modelled according to mixed-mode (combined modes I and II) fracture. The initial model 
further assumed corrosion products form exclusively at the concrete/reinforcement interface. The penetration of corrosion products, non-uniform precipitation of corrosion products, and creep were not accounted for in the initial modelling approach presented in (Michel et al. 2010; Solgaard 2013). The implementation of these reinforcement corrosion related phenomena within a smeared crack modelling approach, are outline in the following sections.

\section{Smeared Crack Modelling Approach}

To overcome the limitations of the discrete crack modelling approach, in particular, the predefined crack path and direction of a single corrosion-induced crack, the model was further developed within a smeared crack modelling approach. However, the formulation of smeared crack approaches in terms of continuous stress-strain relations (for a discontinuous phenomenon such as a corrosioninduced crack) is associated with drawbacks when dealing with time-dependent problems such as reinforcement corrosion. As, the nucleation of one or more corrosion-induced cracks leads to a deterioration of the current stiffness and strength of the concrete domain, subsequent stress and strain distribution depend on the stress and strain history (referred to as history dependency in the present paper).

In this study, the commercial finite element program TNO DIANA was used to simulate crack initiation and propagation using a smeared crack modelling approach. Within the model a multidirectional fixed cracking (MDFC) model was used, which can be combined with time dependent material models, such as e.g. creep. The MDFC model describes cracking using properties regarding tension cut-off, shear retention, and tension softening. In the present study linear tension cut-off was chosen viz. cracking occurs when the major principal tensile stress is larger than the minimum of either tensile strength or a ratio between the tensile and compressive strength. Following the previously developed discrete cracking approach, the shear modulus after cracking was kept constant during simulation and multi-linear softening relations (adopted from Skocek (2010)) are used to describe tension softening. A standard Newton-Raphson method with an energy convergence criterion was used to obtain a solution of the nonlinear problem.

The implementation of penetration of corrosion products into the available pore space of the cementitious matrix surrounding the reinforcement, non-uniform precipitation of corrosion products, and creep within the smeared crack modelling approach is provided in the following sections.

\subsection{Penetration and non-uniform precipitation of corrosion products and creep}

Results of several experimental investigations described in the literature e.g. (Liu \& Weyers 1998; Val et al. 2009; Michel et al. 2011; Pease et al. 2012) indicate both the penetration of corrosion products into the surrounding concrete and non-uniform precipitation of the corrosion products. The penetration of corrosion products into the available pore space of the cementitious matrix surrounding the reinforcement can be attributed to the porous nature of concrete, which allows precipitation of corrosion products to a certain degree without inducing tensile stresses in the concrete. Based on these observations (Michel et al. 2011), penetration and non-uniform precipitation of corrosion products and the effect of creep was implemented in a FE based discrete 
cracking modelling approach e.g. (Pease et al. 2012; Michel et al. 2013; Thybo et al. 2013), which can be adapted for smeared crack modelling approach.

\subsubsection{Penetration of corrosion products}

With the help of x-ray attenuation and digital image correlation measurements (Michel et al. 2011; Pease et al. 2012) were able to directly observe the penetration of corrosion products into the cementitious matrix surrounding the reinforcement reducing the effect of corrosion-induced expansion and, thereby, delaying the stress formation and initiation of cracking. Based on these observations, a conceptual approach to account for the penetration of corrosion products into the available pore space of cementitious material surrounding reinforcement was developed and presented in Michel et al. (2013). It is assumed that a corrosion accommodating region (CAR) around the reinforcement exists, initially denoted $C A R_{0}$, which delays stress formation while filling with corrosion products. Once this initial $C A R_{0}$ is filled with corrosion products, tensile stresses in the surrounding cementitious material increase and potentially lead to the formation of microcracks. These microcracks allow solid corrosion products to penetrate additional pore spaces and further delay corrosion-induced stresses. At some point a maximum size of the $C A R$, denoted as $C A R_{M A X}$, is reached. No corrosion products can penetrate the matrix of the cementitious material beyond that point and all additionally formed corrosion products will introduce tensile stresses and potentially lead to the formation of a macrocrack.

The relationship between $C A R, C A R_{0}$, and $C A R_{M A X}$ was described in Michel et al. (2013):

$C A R=C A R_{0}+\left(C A R_{M A X}-C A R_{0}\right) \kappa$

$\kappa$ is a dimensionless coefficient describing the change in connectivity of accessible pore space inside the $C A R[-]$ and is assumed to vary between 0 and 1 according to:

$\kappa=0 \quad$ if $V_{c p} \leq V_{c p, \min }$

$\kappa=\frac{V_{c p}-V_{c p, \min }}{\left(V_{c p, \max }-V_{c p, \min }\right)^{f p 1}} \quad$ if $V_{c p, \min }<V_{c p} \leq V_{c p, \max }$

$\kappa=1$

if $V_{c p}>V_{c p, \max }$

where $V_{c p}$ is the expanded volume of corrosion products $\left[\mathrm{mm}^{3}\right], V_{c p, m i n}$ is the minimum volume of corrosion products $\left[\mathrm{mm}^{3}\right]$ (Eq. 7) and $V_{c p, \max }$ the maximum volume of corrosion products that can be accommodated in the $C A R\left[\mathrm{~mm}^{3}\right]$ (Eq. 8), and $f p l$ a fitting parameter set to 1 [-].

The values of $t$ in Eq. 7 and 8 are based on experimental observations from x-ray described in (Pease et al. 2012).

$V_{c p, \min }=3 \Delta T \pi l_{A}\left(R^{2}-(R-X(t=1.5))^{2}\right)$

$V_{c p, \max }=3 \Delta T \pi l_{A}\left(R^{2}-(R-X(t=5))^{2}\right)$

(Pease et al. 2012) introduced an adjusted temperature increment, $\Delta T_{C A R}$, instead of $\Delta T$ (see Eq. 4) to account for the penetration of corrosion products. 
$\Delta T_{C A R}=\lambda_{C A R} \Delta T$

$\lambda_{C A R}$ describes the partial penetration of corrosion products [-] into the accessible (pore) space of the cementitious matrix and is defined as follows:

$\lambda_{C A R}=\left(\frac{V_{c p}}{V_{C A R}}\right)^{n} \quad$ if $V_{c p}<V_{C A R}$

$\lambda_{C A R}=1 \quad$ if $V_{c p} \geq V_{C A R}$

where $n$ is an empirical parameter discussed in (Pease et al. 2012) [-] and $V_{C A R}$ the volume of the $C A R\left[\mathrm{~mm}^{3}\right]$. The volume of the $C A R$ is depending on the porosity and accessible volume of the concrete matrix:

$V_{C A R}=\varphi V_{C M}$

where $\varphi$ is the capillary porosity of the concrete material [-], $V_{C M}$ the accessible volume of concrete $\left[\mathrm{mm}^{3}\right]$ depending on the size of $C A R$, see Eq. 5, the radius of the reinforcement, $R[\mathrm{~mm}]$, and the length of the reinforcement which is corroding, $l_{A}[\mathrm{~mm}]$.

$V_{C M}=\pi l_{A}\left((R+C A R)^{2}-R^{2}\right)$

\subsubsection{Non-uniform precipitation of corrosion products}

Among others, (Michel et al. 2012; Pease et al. 2012; Pease et al. 2012) observed that the precipitation of corrosion products was non-uniform along the circumference of the reinforcement although an impressed current was used to enhance the corrosion process. To account for the nonuniform precipitation of corrosion products within a discrete crack modelling approach, a corrosion current density vector, $\boldsymbol{i}_{\text {corr }}$, was introduced in Thybo et al. (2013). By varying the corrosion current density along the circumference of the reinforcement, see Fig. 1, different degrees of reinforcement corrosion were generated i.e. the reduction in reinforcement radius (as well as the partial penetration coefficient (Eq. 10) and the adjusted temperature increment (Eq. 9) depend on both time and location. Introducing $\boldsymbol{i}_{\text {corr }}$ Eq. 1, 3, and 4 are replaced by Eq. 13, 14, and 15, respectively. A detailed explanation of the non-uniform precipitation of corrosion products is presented in Gebreyouhannes and Maekawa (2016) where the variation is explained as the result of the variation in the diffusion properties in the surrounding concrete resulting in a varying penetration of corrosion products into the concrete along the interface and thus resulting in varying stresses, deformations and consequently varying conditions for the corrosion process.

$$
\begin{aligned}
& \boldsymbol{X}(\boldsymbol{t})=\boldsymbol{R}_{\mathbf{0}}-\boldsymbol{R}_{\mathbf{1}}=\frac{M \boldsymbol{i}_{\text {corr }} \Delta t}{(z F \rho)} \\
& \eta_{\text {lin }}\left(\boldsymbol{R}_{\mathbf{0}}-R_{1}\right)=\boldsymbol{R}_{\mathbf{2}}-\boldsymbol{R}_{\mathbf{0}} \\
& \eta_{\text {lin }}=\alpha \Delta T
\end{aligned}
$$




\subsubsection{Creep}

To account for creep within the FE based smeared crack modelling approach, an effective modulus of elasticity for concrete was used according to Eurocode (2008), see Eq. 16. The implementation of creep was based on the assumption that the models concerning creep in larger volumes of concrete are also applicable for the volume size considered in the present study.

$E_{c, e f f}=\frac{E_{c}}{1+\varphi\left(t_{\text {age }}, t_{0}\right)}$

Where $E_{c, e f f}$ is the effective modulus of elasticity [MPa], $E_{c}$ the tangent modulus of elasticity [MPa], $\varphi\left(t_{a g e}, t_{0}\right)$ the creep coefficient [-], $t_{\text {age }}$ the age of the concrete [days] and $t_{0}$ the time at loading [days].

\subsection{Convergence of mesh}

To investigate the impact of number of elements in the concrete domain and the number of corroding steel elements along the circumference of the reinforcement on corrosion-induced crack widths, a convergence analysis was carried out. Fig. 2 illustrates a plot of the mesh highlighting the concrete, steel, and corroding steel domain. Three nodded triangular plane stress elements were used to discretize both the concrete and steel domain, while four-nodded quadrilateral plane stress elements where used to discretize the corroding steel domain. A zoom of the corroding steel domain is illustrated underlining that the corroding steel domain consists of several elements in the radial direction. The number of elements in radial direction depends on the number of 'time steps' selected during the simulation (see section 4.3).

For the convergence analysis the number of elements within the concrete domain was varied between approximately 4000 and 49000 elements. Results of the analysis for a thickness of the corroding steel domain of $0.035 \mathrm{~mm}$ are presented in Fig. 3 and have been normalised with respect to the results for 49082 elements. A maximum deviation of approximately $2 \%$ is observed when increasing the number of elements from around 30000 to 49082 . Thus, it was concluded that approximately 30000 elements in the concrete domain are sufficient to model corrosion-induced cracking and it is actually possible to reduce the number of elements to optimize computational time without compromising accuracy of the simulations significantly. For the convergence analysis of the number of elements along the circumference of the reinforcement, 24, 36, 48, 148, and 192 elements were chosen to discretize the corroding steel domain. Results of the analysis are illustrated in Fig. 4 for a thickness of the corroding steel domain of $0.035 \mathrm{~mm}$ and were normalised with respect to the results for 192 elements. It is seen that between 48 and 192 elements a deviation of less than $2 \%$ is observed. Therefore, it was concluded that 48 elements along the circumference of the reinforcement are sufficient for modelling corrosion-induced cracking without compromising accuracy. The influence of number of corroding steel elements in radial direction and the effect of number of elements in the steel domain was not investigated.

\subsection{History dependency}

In the following the 'history dependency' of the developed smeared crack modelling approach was investigated comparing initiation time and surface crack widths varying the number of intermediate 'load steps'. In the following the number of intermediate 'load steps' is referred to as 'time steps'. The applied number of 'time steps' for the various simulations, is schematized in Table 4.1, along 
with results of surface crack width, which are also visualised in Fig. 5. The input parameters for the various simulations are given in Table 4.2.

Table 4.1 Overview of time-to crack initiation and surface crack width after 20 days for varying numbers of 'time steps'.

\begin{tabular}{lccc}
\hline No. of 'time steps' & $\begin{array}{c}\text { Time to crack initiation } \\
\text { [days] }\end{array}$ & $\begin{array}{c}\text { Deviation of time at first } \\
\text { given crack value } \\
{[\%]}\end{array}$ & $\begin{array}{c}\text { Deviation of surface crack width } \\
\text { after 20 days } \\
{[\%]}\end{array}$ \\
\hline 1 & - & - & 29.1 \\
3 & $12^{*}$ & 20.0 & 5.4 \\
5 & $12^{*}$ & 20.0 & 5.1 \\
20 & $11^{*}$ & 10.0 & 2.5 \\
40 & 10.5 & 5.0 & 2.0 \\
80 & 10.25 & 2.5 & 1.0 \\
200 & 10 & 0 & 0 \\
\hline "In Fig. 9 it is seen that the crack initiates earlier, however this is the first given value due to the low number of \\
'time steps'.
\end{tabular}

Table 4.2 Input parameters for smeared crack modelling approach to investigate varying number of 'time steps'.

\begin{tabular}{llcc}
\hline & Parameter & Value & Dimension \\
\hline Length & $\mathrm{L}$ & 23 & $\mathrm{~mm}$ \\
Width & $\mathrm{W}$ & 100 & $\mathrm{~mm}$ \\
Height & $\mathrm{H}$ & 100 & $\mathrm{~mm}$ \\
Cover layer & $\mathrm{C}$ & 45 & $\mathrm{~mm}$ \\
Reinforcement diameter & $\mathrm{D}$ & 10 & $\mathrm{~mm}$ \\
Water-to-cement ratio & $\mathrm{w} / \mathrm{c}$ & 0.5 & - \\
Concrete compressive strength & $f_{c m}$ & 45 & $\mathrm{MPa}$ \\
Tangent modulus of elasticity - concrete & $E_{c}$ & 36.272 & $\mathrm{GPa}$ \\
Shear stiffness & $G_{c}$ & 10 & $\mathrm{GPa}$ \\
Poisson ratio - concrete & $\mu_{c}$ & 0.2 & - \\
Modulus of elasticity - steel & $E_{s}$ & 210 & $\mathrm{GPa}$ \\
Poisson ratio - steel & $\mu_{s}$ & 0.3 & - \\
Modulus of elasticity - corrosion products & $E_{c o r r}$ & 2 & $\mathrm{GPa}$ \\
Poisson ratio - corrosion products & $\mu_{\text {corr }}$ & 0.2 & - \\
Relative humidity & $R H$ & 65 & $\%$ \\
Molar mass - steel & $M_{F e}$ & 55.845 & $\mathrm{~g} / \mathrm{mol}$ \\
Valence & $z$ & 2 & - \\
Steel density & $\rho_{\text {steel }}$ & 7.86 & $\mathrm{~g} / \mathrm{cm}^{3}$ \\
Faraday's constant & $F$ & 96485 & $\mathrm{~A} \cdot \mathrm{s} / \mathrm{mol}$ \\
Mean corrosion current density & $i_{\text {corr mean }}$ & 0.0001 & $\mathrm{~A} / \mathrm{cm}^{2}$ \\
Min. corrosion accommodating region & $C A R_{0}$ & 0.14 & $\mathrm{~mm}$ \\
Max. corrosion accommodating region & $C A R_{M A X}$ & 0.28 & $\mathrm{~mm}$ \\
Min. volume of corrosion products in $C A R$ & $V_{c p \text {, min }}$ & 7.15 & $\mathrm{~mm}$ \\
Max. volume of corrosion products in $C A R$ & $V_{c p \text { max }}$ & 23.8 & $\mathrm{~mm}$ \\
Linear expansion coefficient & $\eta_{\text {lin }}$ & 0.7 & - \\
Fictitious thermal expansion coefficient & $\alpha$ & 1 & - \\
\hline & & & \\
& $\alpha$ & & \\
\hline
\end{tabular}

From the results presented in Fig. 5 it can be seen that both surface crack width and time-to crack initiation depend on the number of 'time steps' (deformation history) in the smeared crack modelling approach. In general, it is observed that with decreasing number of 'time steps' insufficient and incorrect information on time-to crack initiation, crack width development over time, and final crack width are obtained. More realistic crack width development and final crack width are obtained with the modelling approach, when more than three 'time steps' are used. However, larger deviations with respect to the time-to crack initiation are still observed for an insufficient number of 'time steps'. This relation is highlighted in Table 4.1, where it can be observed that the final surface crack width (surface crack width at 20 days) is less affected by the 
number of 'time steps' compared to the time-to crack initiation. The results presented in Table 4.1 indicate that the number of 'time steps' should be based on desired accuracy with respect to crack width development and time-to crack initiation. In order to minimise computational time and at the same time maintain an acceptable accuracy it was chosen to run simulations in the following with 40 'time steps'. For this number of 'time steps', approximately 5\% and $2 \%$ deviation with respect to time-to crack and final surface crack width are expected, respectively (compared to 200 'time steps').

\section{Comparison between experimental and numerical results}

To demonstrate the applicability of the developed FE based smeared crack modelling approach (including the penetration of solid corrosion products into the cementitious matrix, non-uniform precipitation of corrosion products, and creep) to predict corrosion-induced deformations and crack formation, numerical simulations were compared to two experimental studies: (1) results of digital image correlation (DIC) measurements presented in (Pease et al. 2012; Michel et al. 2013) and (2) experimental observations from $\mathrm{Vu}$ et al. (2005). In addition, results of the previously developed discrete crack modelling approach were also compared to predictions of the smeared crack modelling approach.

\subsection{Experimental investigations}

Pease et al. (2012) used digital image correlation (DIC) measurements to study the formation of corrosion products and corrosion-induced deformation in reinforced mortar specimens $(\mathrm{w} / \mathrm{c}=0.5)$ under accelerated corrosion conditions. Each specimen was $23 \mathrm{~mm} \times 100 \mathrm{~mm} \times 100 \mathrm{~mm}$ and a smooth $10 \mathrm{~mm}$ steel rod was placed in the centre as reinforcement. During the experiments, the specimens were placed in an acrylic pond containing tap water and a volumetric flask was used to maintain the water level at about $1 \mathrm{~cm}$ below the reinforcement. To enhance the reinforcement corrosion process, a DC regulator was used to impress a constant electrical current $\left(100 \mu \mathrm{A} / \mathrm{cm}^{2}\right)$ through the counter electrode (activated titanium mesh). Deformations were measured using DIC technique allowing for crack measurements on the specimen surface, see e.g. Pease et al. (2012).

For the DIC measurement technique, digital images were repeatedly captured at 10 minute intervals using a Nikon D3X 24.5 megapixel $(6048 \times 4032$ pixel) camera body with a $60 \mathrm{~mm}$ focal length macro lens (AF-S Micro Nikkor $60 \mathrm{~mm}$ f $/ 2.8 \mathrm{G}$ ED). Prior to initiation of accelerated corrosion testing, three images were captured of the specimen surface, with a fourth image including a scale. The lens was placed $60 \mathrm{~mm}$ from the specimen surface, resulting in images with dimensions of approximately $31 \times 41 \mathrm{~mm}^{2}$, with each pixel representing $7.8 \times 7.8 \mu \mathrm{m}^{2}$ of physical space (Pease et al. 2012).

Captured images were input into a commercially available software package (GOM 2009), which utilizes a previously applied stochastic speckle pattern to identify unique regions, called facets, on the specimen surface at each measurement time. The software tracks the movements of the facets and utilizes standard DIC techniques to compute deformations of the specimen surface. Additional information on the hardware used and the DIC technique is available in Pereira et al. (2011) and Pease et al. (2006), respectively Pease et al. (2012). 
In addition, a trial test, to assess DIC measurement accuracy, was conducted by placing two mortar prisms side-by-side with flat faces touching each other. Prisms were fixed to a micrometer setup with $1 \mu \mathrm{m}$ gradations with one prism stationary and the second moving with controlled distances. Two $2.5 \mathrm{~mm}$ extensiometers were used to provide comparative displacement measurements between the fixed and moving mortar prisms. The moving prism was translated by the micrometer setup to varying locations. At each location 3 digital images and 20 extensiometer measurements were recorded. A maximum difference of $0.29 \mu \mathrm{m}$ was found for deformations from 0 to $26.2 \mu \mathrm{m}$ comparing results of DIC measurement technique and extensiometer measurements Pease et al. (2012).

The accelerated corrosion test was stopped when the first macro-crack near the concrete/reinforcement interface was observed. For more information about preparation of the specimens, test setup, and measurement technique reference is made to Pease et al. (2012).

To fit the experimental observations, a vector describing the non-uniform corrosion along the circumference of the reinforcement was defined. The non-uniform corrosion current density along the circumference of the reinforcement was estimated using the experimental deformations after three days of accelerated corrosion as a starting point. A comparison between measured deformations after three days of accelerated corrosion and applied corrosion current density along the circumference of the reinforcement is illustrated in Fig. 6. The average corrosion current density was $100 \mu \mathrm{A} / \mathrm{cm} 2$ and local variations may be attributed to factors such as reinforcement surface condition and moisture distribution around the reinforcement. In addition, the concrete tensile strength, $f_{c t m}$, was chosen to be $4.5[\mathrm{MPa}$ ] and the non-physical modelling parameters $f p 1$ and $n$ were set to 2.2 and 1.8 , respectively. An overview of the input parameters for the smeared crack modelling approach is given in Table 4.2.

Similar to Pease et al. (2012), Vu et al. (2005) conducted accelerated corrosion tests to study the formation of corrosion-induced concrete cover cracks. Reinforced concrete slabs with w/c of 0.45 , 0.5 , and 0.58 were submersed in $5 \%$ sodium chloride $(\mathrm{NaCl})$ solution and tested under accelerated conditions applying a constant current density of $100 \mu \mathrm{A} / \mathrm{cm}^{2}$. Corrosion-induced cracks were measured using a combination of magnifying glass and displacement transducers. Testing was stopped when a crack width of $1.0-1.5 \mathrm{~mm}$ at the concrete surface was measured. More detailed information on specimen preparation, material properties, and experimental setup are provided in $\mathrm{Vu}$ et al. (2005).

To simulated the experimental observations described in Vu et al. (2005), i.e. time-to crack initiation and surface crack width, input parameters for the model described in Table 5.1 were used. In addition, the concrete tensile strength compressive strength and volume expansion coefficient were set to 4.16 MPa, 43 MPa and 2,94, respectively, as provided in Vu et al. (2005). Furthermore, the non-physical modelling parameters $f p 1$ and $n$ were set to 2.2 and 1.8, respectively. Further, Poisson's ratio and elastic modulus of corrosion products were set to 0.2 and $2 \mathrm{GPa}$, respectively, as e.g. provided in (Solgaard et al. 2013, Caré 2008). 
Table 5.1 Input parameters for smeared crack modelling approach comparing to experimental data from Vu et al. (2005).

\begin{tabular}{llcc}
\hline & Parameter & Value & Dimension \\
\hline Length & $\mathrm{L}$ & 1000 & $\mathrm{~mm}$ \\
Width & $\mathrm{W}$ & 156 & $\mathrm{~mm}$ \\
Height & $\mathrm{H}$ & 250 & $\mathrm{~mm}$ \\
Cover layer & $\mathrm{C}$ & 50 & $\mathrm{~mm}$ \\
Reinforcement diameter & $\mathrm{D}$ & 16 & $\mathrm{~mm}$ \\
Water-to-cement ratio & $\mathrm{w} / \mathrm{c}$ & 0.5 & - \\
Tangent modulus of elasticity - concrete & $E_{c}$ & 36.272 & $\mathrm{GPa}$ \\
Shear stiffness & $G_{c}$ & 10 & $\mathrm{GPa}$ \\
Poisson ratio - concrete & $\mu_{c}$ & 0.2 & - \\
Modulus of elasticity - steel & $E_{s}$ & 210 & $\mathrm{GPa}$ \\
Poisson ratio - steel & $\mu_{s}$ & 0.3 & - \\
Relative humidity & $R H$ & 65 & $\%$ \\
Molar mass - steel & $M_{F e}$ & 55.845 & $\mathrm{~g} / \mathrm{mol}$ \\
Valence & $z$ & 2 & - \\
Steel density & $\rho_{s t e e l}$ & 7.86 & $\mathrm{~g} / \mathrm{cm}^{3}$ \\
Faraday's constant & $F$ & 96485 & $\mathrm{~A} \cdot \mathrm{s} / \mathrm{mol}$ \\
Mean corrosion current density & $i_{c o r r}$ mean & 0.0001 & $\mathrm{~A} / \mathrm{cm}^{2}$ \\
Min. corrosion accommodating region & $C A R o$ & 0.14 & $\mathrm{~mm}$ \\
Max. corrosion accommodating region & $C A R_{M A X}$ & 0.22 & $\mathrm{~mm}$ \\
Min. volume of corrosion products in $C A R$ & $V_{c p, \min }$ & 2351 & $\mathrm{~mm}$ \\
Max. volume of corrosion products in $C A R$ & $V_{c p \text { max }}$ & 705 & $\mathrm{~mm}$ \\
Fictitious thermal expansion coefficient & $\alpha$ & 1 & - \\
\hline
\end{tabular}

\subsection{Results and discussion}

The ability of the presented smeared crack modelling approach is discussed with respect to three criteria: 1) corrosion-induced deformations near the concrete/reinforcement interface, 2) corrosioninduced crack patterns, and 3) time-to surface crack initiation and surface crack width. To quantify the ability of the model to simulate corrosion-induced deformations and cracks in the vicinity of the concrete/reinforcement interface, experimental results of digital image correlation measurements presented in Michel et al. (2013) were used. Numerical predictions of time-to surface crack initiation and surface crack width were compared to experimental data presented in Vu et al. (2005). Comparisons between experimentally observed corrosion-induced deformations along the circumference of the reinforcement and numerical predictions using the presented smeared crack modelling approach and the previously developed discrete crack modelling approach (Pease et al. 2012; Thybo et al. 2013) are presented in Fig. 8. Numerical and experimental results are given after three, six, and nine days of accelerated corrosion in polar coordinates (see also Fig.7). As can be seen from the results presented in Fig. 7, excellent agreement (with respect to shape and magnitude) between experimentally observed and numerically predicted corrosion-induced deformations is found for six and nine days of accelerated corrosion.

In addition, experimentally observed microcracks (by means of DIC) due to accelerated corrosion are illustrated in Fig. 8. DIC allows thereby for identification of cracks as zones with localized strain, i.e. areas in red and light blue in Fig. 8. Three corrosion-induced microcracks (with crack widths between approximately two and ten $\mu \mathrm{m}$ ) and considerable damage along the circumference of the reinforcement can be identified in Fig. 8. The microcracks formed at the reinforcement, extend around 10 to $15 \mathrm{~mm}$ in the mortar, and propagated towards the surface over time. For comparison, the crack pattern obtained by the presented smeared crack modelling approach and previously developed discrete crack modelling approach is given in Fig. 10 and Fig. 9, respectively. 
Similar crack pattern and corrosion-induced damage along the circumference of the reinforcement are obtained with the smeared crack modelling approach, while only one corrosion-induced crack is formed along the predefined crack path in the discrete crack modelling approach. Furthermore, extensive damage along the circumference of the reinforcement, in particular on the right side, and micro-cracking are observed in the smeared crack modelling approach (see Fig. 10), which is not captured by the discrete crack modelling approach (see Fig. 9). In particular, three microcracks, which formed at the reinforcement and propagate towards the surface, can be observed in Fig. 10. While the direction of the microcracks is not completely in agreement with the experimental observations, the extent of the microcracks is in good agreement with numerical predictions of the smeared crack modelling approach. However, it should be noted that results of the presented DIC measurement technique only provide information on corrosion-induced deformations and cracking on the specimen surface, i.e. details on corrosion-induced deformations and cracking within the specimen cannot be obtained with DIC. For additional validation of the presented modelling approach (accelerated) corrosion test may be undertaken in e.g. a $\mu$-CT allowing for the observation of corrosion-induced deformations and cracking within the specimen.

Finally, Fig. 11 illustrates a comparison of experimentally observed corrosion-induced surface crack width (Vu et al. 2005) and numerical predictions with the presented smeared crack modelling approach (taking into account and neglecting the penetration of corrosion products into the surrounding concrete). It can be clearly seen from the presented results that the model is able to accurately capture the time-to crack initiation when the penetration of corrosion products into the surrounding concrete is taken into account. Larger deviations between experimental observations and numerical predictions with respect to the time-to crack initiation are found when the penetration of corrosion products into the surrounding concrete is neglected; please note the logarithmic time scale in Fig. 11. While the time-to crack initiation is accurately captured with the presented smeared crack modelling approach, some deviations are found between experimentally observed and numerically predicted surface crack opening. Those deviations maybe be explained due to lacking information on fracture mechanical properties, in particular, the softening behaviour of the concrete material, as only the tensile strength was provided in $\mathrm{Vu}$ et al. (2005).

\subsubsection{Influence of elastic modulus of corrosion products}

Deterioration models, such as the presented smeared crack modelling approach, developed to better understand corrosion-induced cracking processes in reinforced concrete, have highlighted a key parameter in the cracking process - namely, the elastic properties of reinforcement corrosion products (Molina et al. 1993, Solgaard 2013). Citing a lack of experimental observations (Molina et al. 1993) assumed water comprised the majority of corrosion products and therefore used water's elastic properties (2 GPa elastic modulus, 0.5 Poisson's ratio) to characterize the mechanical properties of corrosion products. Direct measurement of elastic properties of corrosion products is complicated due to the materials' stratified lamina nature. However, recently works attempted to quantify properties of reinforcement corrosion products (Ouglova et al. 2006; Caré et al. 2008; Pease et al. 2012). Generally it was concluded that the elastic properties depend on the type and conditions under which corrosion products are formed e.g. degree of confinement, supply of oxygen, 
etc. In Pease et al. (2012) a discrete crack modelling approach was used to compare experimental observations of crack widths near the concrete/reinforcement interface (obtained by means of digital image correlation) with numerical predictions. Within their studies, (Pease et al. 2012) found that elastic properties of the corrosion products between 2 and 20 GPa provided the best fit for the experimental data. Similar to Pease et al. (2012), the smeared crack modelling approach presented in this study was used to investigate the influence of the elastic properties of corrosion products on the time-to corrosion-induced cracking and development of surface cracks comparing numerical predictions and experimental observations from Vu et al. (2005), see Fig. 11. Elastic properties of corrosion products were thereby varied between 0.2 and $200 \mathrm{GPa}$.

Fig. 12 illustrates numerical results of the smeared crack modelling approach and experimental results for varying elastic properties of the corrosion products. From the presented results in Fig. 12, it can be seen that the elastic properties of the corrosion products affect both time-to corrosioninduced cracking and development of surface crack width. However, the impact on the time-to corrosion-induced cracking is lower than the influence on the development of the surface crack width, in particular for elastic properties in the range of 0.2 to $20 \mathrm{GPa}$. Significant changes in the time-to crack initiation and development of surface crack width are observed for elastic properties in the range of $200 \mathrm{GPa}$, in which case the smeared crack modelling approach considerably overestimates the experimental observations both with respect to time-to crack initiation and development of surface crack width.

\section{Summary and Conclusions}

In the present paper a finite element based smeared crack modelling approach was introduced to simulate corrosion-induced concrete damage. The presented modelling approach utilizes a thermal analogy to mimic the expansive nature of solid corrosion products and furthermore takes into account the penetration of corrosion products into the surrounding concrete, non-uniform precipitation of corrosion products, and creep. To demonstrate the applicability of the presented modelling approach, numerical predictions in terms of corrosion-induced deformations as well as formation and propagation of micro- and macrocracks were compared to experimental data obtained by digital image correlation and published in the literature. From the presented studies using the developed smeared crack modelling approach it may be concluded that:

1 The time-to crack initiation depends on the number of 'time steps' (deformation history) in the smeared crack modelling approach. In general, it is observed that with decreasing number of 'time steps' insufficient and incorrect information on time-to crack initiation, crack width development over time, and final crack width are obtained. Preliminary modelling results indicate that the chosen number of 'time steps' should be based on desired accuracy with respect to crack width development and time-to crack initiation.

2 Excellent agreements between experimentally observed and numerically predicted crack patterns at the micro and macro scale indicate the capability of the modelling approach to accurately capture corrosion-induced damage phenomena in reinforced concrete. Moreover, good agreements were also found between experimental and numerical data for corrosion- 
induced deformations along the circumference of the reinforcement. In particular, the assumption of non-uniform corrosion around the circumference of the reinforcement let to a considerable improvement of numerical predictions concerning corrosion-induced deformations in comparison to previously presented modelling approaches.

3 The penetration of corrosion products into the available pore space of the cementitious matrix surrounding the reinforcement has a considerable effect on the time-to crack initiation. While in the present study the effect was demonstrated for accelerated corrosion conditions, the influence is even more pronounced under natural corrosion conditions, where corrosion current densities in the range of approximately 0.1 to $1 \mu \mathrm{A} / \mathrm{cm}^{2}$ can be expected. It should be noted that in the present study homogeneous diffusion properties governing the penetration of corrosion products into the concrete were applied, while a more detailed study (Gebreyouhannes and Maekawa 2016) applied inhomogeneous diffusion properties providing an underlying explanation for the varying precipitation of corrosion properties along the circumference of the reinforcement.

4 The elastic properties of the corrosion products affect both time-to corrosion-induced cracking and development of surface crack width. However, the impact on the time-to corrosion-induced cracking is lower than the influence on the development of the surface crack width, in particular for elastic properties in the range of 0.2 to $20 \mathrm{GPa}$. Within the present study values for the elastic modulus of corrosion products between 2.0 and 20.0 GPa provided most accurate fits to experimental results both with respect to time-to crack initiation and development of surface crack width.

Despite the good results found in the present study, future investigations should focus on improving modelling considerations regarding among others $3 \mathrm{D}$ analyses including non-uniform corrosion along the reinforcement as well as the inhomogeneous nature of concrete.

\section{Acknowledgements}

The authors gratefully acknowledge the financial support of the Danish Expert Centre for Infrastructure Constructions. Further, the authors would like to thank Bradley J. Pease for contributing with experimental data.

\section{Compliance with Ethical Standards}

The first author has received funding from the Danish Expert Centre for Infrastructure Constructions. No grant number exists.

\section{Conflict of Interest Statement}

The authors declare that they have no conflict of interest. 


\section{References}

Alonso C, Andrade C, Rodriguez J, Diez JM (1998) Factors controlling cracking of concrete affected by reinforcement corrosion. Materials and Structures 45:435-441. doi: 10.1007/BF02480466

Andrade C, Alonso C, Molina FJ (1993) Cover cracking as a function of bar corrosion: Part IExperimental test. Materials and Structures 26:453-464. doi:10.1007/BF02472805

Bazant ZP (1979) Physical Model for Steel Corrosion in Concrete Sea Structures - Theory. Journal of the Structural Division-ASCE, 105:1137-1153

Biondini F, Vergani M (2012) Damage modeling and nonlinear analysis of concrete bridges under corrosion. In: Proceedings of 6th International Conference on Bridge maintenance, safety and management (IABMAS), Lake Como

Bohner E, Müller HS, Bröhl S (2010) Investigations on the mechanism of concrete cover cracking due to reinforcement corrosion. In: Proceedings for FraMCos-7-7th International Conference on Fracture Mechanics of Concrete and Concrete Structures, Jeju

Cabrera JG (1996) Deterioration of Concrete Due to Reinforcement Steel Corrosion. Cement and Concrete Composites 18: 47-59. doi:10.1016/0958-9465(95)00043-7

Care S, Nguyen QT, L'Hostis V, Berthaud Y (2008). Mechanical properties of the rust layer induced by impressed current method in reinforced mortar. Cement and Concrete Research 38:1079-1091. doi:10.1016/j.cemconres.2008.03.016

Chernin L, Val DV, Volokh KY (2010). Analytical modelling of concrete cover cracking caused by corrosion of reinforcement. Materials and Structures 43:543-556. doi: 10.1617/s11527009-9510-2

Concrete Structures, DS/S-19000 Eurocode (2008) Eurocode 2: Design of Concrete Structures - Part 1-1: General Rules and Rules for Buildings

Gebreyouhannes E, Maekawa K (2016). Nonlinear Gel Migration in Cracked Concrete and Broken Symmetry of Corrosion Profiles. Journal of Advanced Concrete Technology 14:271-286. doi: $10.3151 /$ jact.14.271

GOM (2009) Aramis user manual - Software, Aramis v6.1 and higher. GOM Optical Measuring Techniques.

Koleva DA, Hu J, Fraaij ALA, Stroeven P, Boshkov N, de Wit JHW (2006) Quantitative characterisation of steel/cement paste interface microstructure and corrosion phenomena in mortars suffering from chloride attack. Corrosion Science 48:4001-4019. doi: 10.1016/j.corsci.2006.03.003

Küter A (2008) Management of Reinforcement Corrosion. Dissertation, Technical University of Denmark

Liu Y, Weyers RE (1998) Modeling the Time-to-Corrosion Cracking in Chloride Contaminated Reinforced Concrete Structures. ACI Materials Journal 95:675-681.

Michel A, Pease BJ, Geiker MR, Stang H, Olesen JF (2011) Monitoring reinforcement corrosion and corrosion-induced cracking using non-destructive $\mathrm{x}$-ray attenuation measurements. Cement and Concrete Research 41:1085-1094. doi: 10.1016/j.cemconres.2011.06.006

Michel A, Pease BJ, Peterova A, Geiker MR, Stang H, Thybo AEA (2013) Penetration of corrosion products and corrosion-induced cracking in reinforced cementitious materials: 
experimental investigations and numerical simulations. Cement and Concrete Composite 47:75-86. doi: 10.1016/j.cemconcomp.2013.04.011

Michel A, Pease BJ, Peterova A, Geiker MR (2012) Experimental determination of the penetration depth of corrosion products and time to corrosion-induced cracking in reinforced cement based materials. In: Proceedings of International Congress on Durability of Concrete, Trondheim

Michel A, Solgaard AOS, Geiker MR, Stang H, Olesen JF (2010) Modeling Formation of Cracks in Concrete Cover due to Reinforcement Corrosion. In: Proceedings for FraMCos-7-7th International Conference on Fracture Mechanics of Concrete and Concrete Structures, Jeju

Molina FJ, Alonso C, Andrade C (1993) Cover cracking as a function of rebar corrosion: Part 2-Numerical model. Materials and Structures 26:532-548. doi 10.1007/BF02472864

Noghabai K. (1999) FE-Modelling of cover splitting due to corrosion by use of inner softening band. Materials and Structures 32:486-491. doi: 10.1007/BF02481632

Ouglova A, Berthaud Y, Francois M, Foct F (2006). Mechanical properties of an iron oxide formed by corrosion in reinforced concrete structures. Corrosion Science, 48:3988-4000. doi: 10.1016/j.corsci.2006.03.007

Pease BJ, Geiker MR, Stang H, Weiss WJ (2006) Photogrammetric Assessment of Flexure Induced Cracking of Reinforced Concrete Beams under Service Loads. In: Proceedings of the Second International RILEM Symposium : Advances in Concrete through Science and Engineering, Québec City

Pease BJ, Michel A, Thybo AEA, Stang H (2012) Estimation of elastic modulus of reinforcement corrosion products using inverse analysis of digital image correlation measurements for input in corrosion-induced cracking model. In: Proceedings of 6th International Conference on Bridge maintenance, safety and management (IABMAS), Lake Como

Pease BJ, Michel A, Stang H (2012) Quantifying movements of corrosion products in reinforced concrete using x-ray attenuation measurements. In: Proceedings for 2nd International Conference on Microdurability, Amsterdam

Pereira EB, Fischer G, Barros JA (2011) Image-based detection and analysis of crack propagation in cementitious composites. In: Proceedings of International RILEM Conference On Advances In Construction Materials Through Science and Engineering, Hong Kong

Rendell F, Jauberthie R, Grantham M (2002) Deteriorated Concrete: Inspection and Physicochemical Analysis. Thomas Telford Ltd.

Skocek J (2010) Fracture propagation in cementitious materials Multi-scale approach: measurements and modeling. Dissertation, Technical University of Denmark

Solgaard AOS (2013) Corrosion of reinforcement bars in steel fibre reinforced concrete structures. Dissertation, Technical University of Denmark

Solgaard AOS, Michel A, Geiker MR, Stang H (2013). Concrete cover cracking due to uniform reinforcement corrosion. Materials and Structures 46:1781-1799. doi: 10.1617/s11527-013-0016-6

Thybo AEA, Michel A, Stang H (2013) Modeling of Corrosion-induced Concrete Damage. In: Proceedings for FraMCos-8 -8th International Conference on Fracture Mechanics of Concrete and Concrete Structures, Toledo 
Val DV, Chernin L, Stewart MG (2009) Experimental and numerical investigation of corrosion-induced cover cracking in reinforced concrete structures. Journal of Structural Engineering 135:376-385. doi: 10.1061/(ASCE)0733-9445(2009)135:4(376)

Vu K., Stewart MG, Mullard J (2005). Corrosion-induced cracking: experimental data and predictive models. ACI Structural Journal 102:719-726.

Zhao Y, Dai H, Ren H, Jin W (2012). Experimental study of the modulus of steel corrosion in a concrete port. Corrosion Science 56:17-25. doi: 10.1016/j.corsci.2011.11.004 
Fig. 1 Load application (left) and basic geometrical considerations to model non-uniform formation of corrosion products (right) in the smeared crack model, from Thybo et al. (2013)

Fig. 2 Plot of mesh

Fig. 3 Convergence plot of elements in concrete

Fig. 4 Convergence plot of elements along perimeter of reinforcement

Fig. 5 Modelled corrosion-induced surface crack widths for varying number of 'time steps'

Fig. 6 Measured deformations (solid line) along the circumference of the reinforcement after three days of accelerated corrosion and corresponding estimated non-uniform corrosion current density (dashed line)

Fig. 7 Comparison of corrosion-induced deformations measured by DIC with numerical results obtained from a previously developed discrete cracking modelling approach (Michel et al. 2013) and the presented smeared crack modelling approach assuming non-uniform corrosion

Fig. 8 Corrosion-induced cracks in reinforced specimens after nine days of accelerated corrosion, please note: only part of the test specimen is illustrated

Fig. 9 Modelled crack development using the discrete crack modelling approach

Fig. 10 Modelled crack development using the smeared crack modelling approach

Fig. 11 Comparison of corrosion-induced surface cracking presented in $\mathrm{Vu}$ et al. (2005) with numerical results applying the presented smeared crack modelling approach (with and without penetration of corrosion products into the surrounding concrete)

Fig. 12 Comparison of corrosion-induced surface crack widths for different elastic moduli of corrosion products using a smeared crack modelling approach 


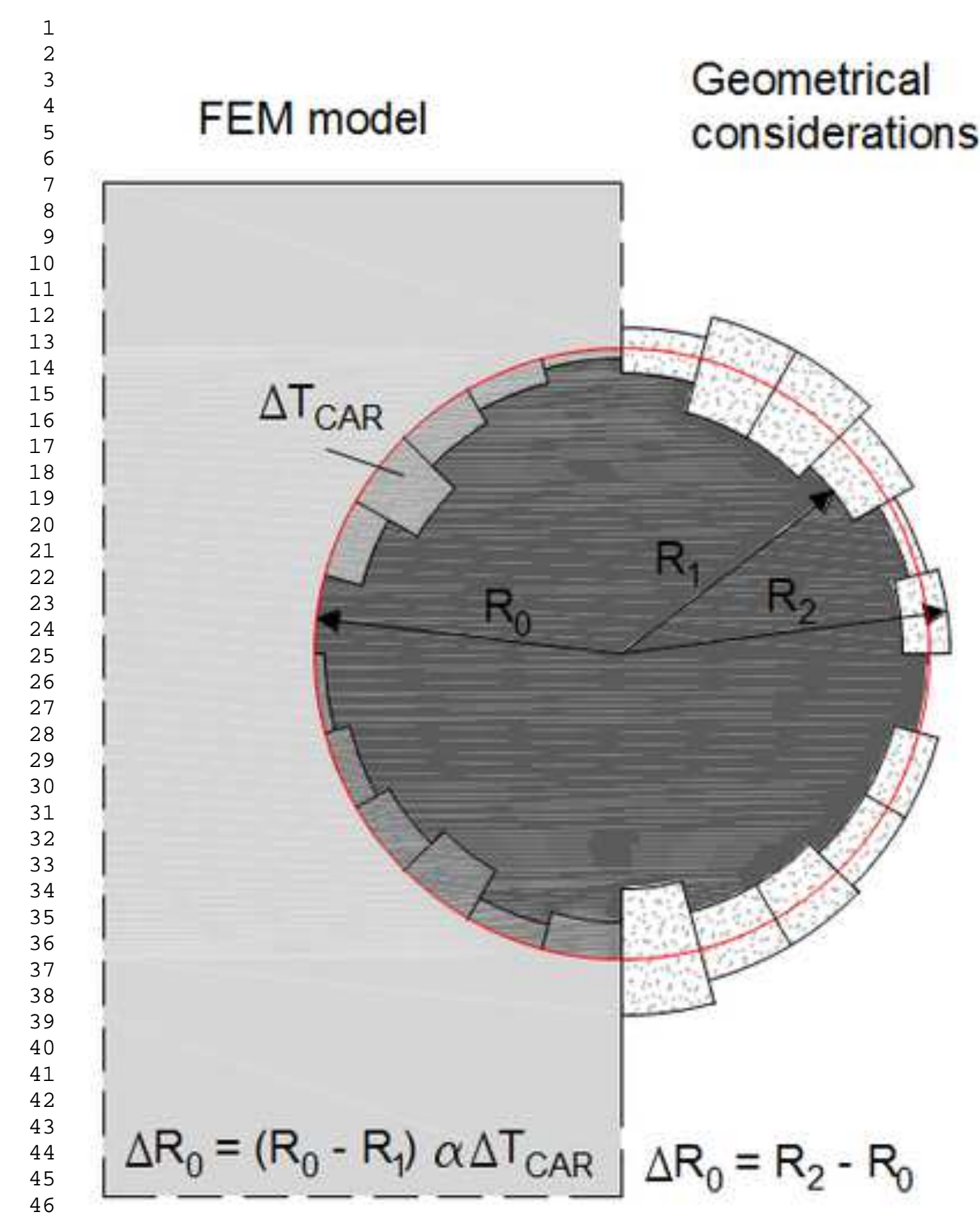

Original size of reinforcement

$\square$ Non-corroded reinforcement

: Expanded corrosion layer

$\square$ Corroded reinforcement

$\square$ Semi-infinite concrete body 


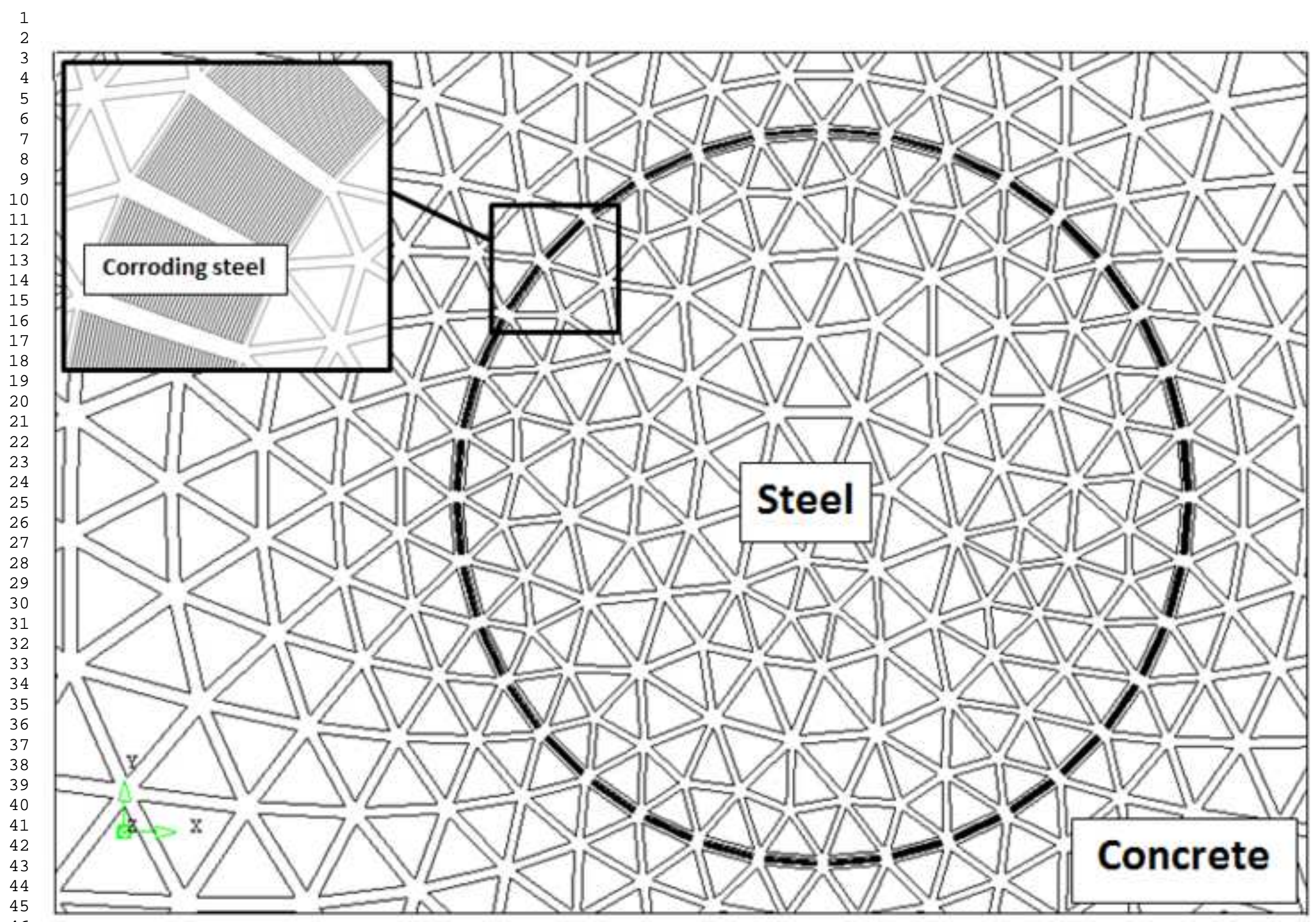




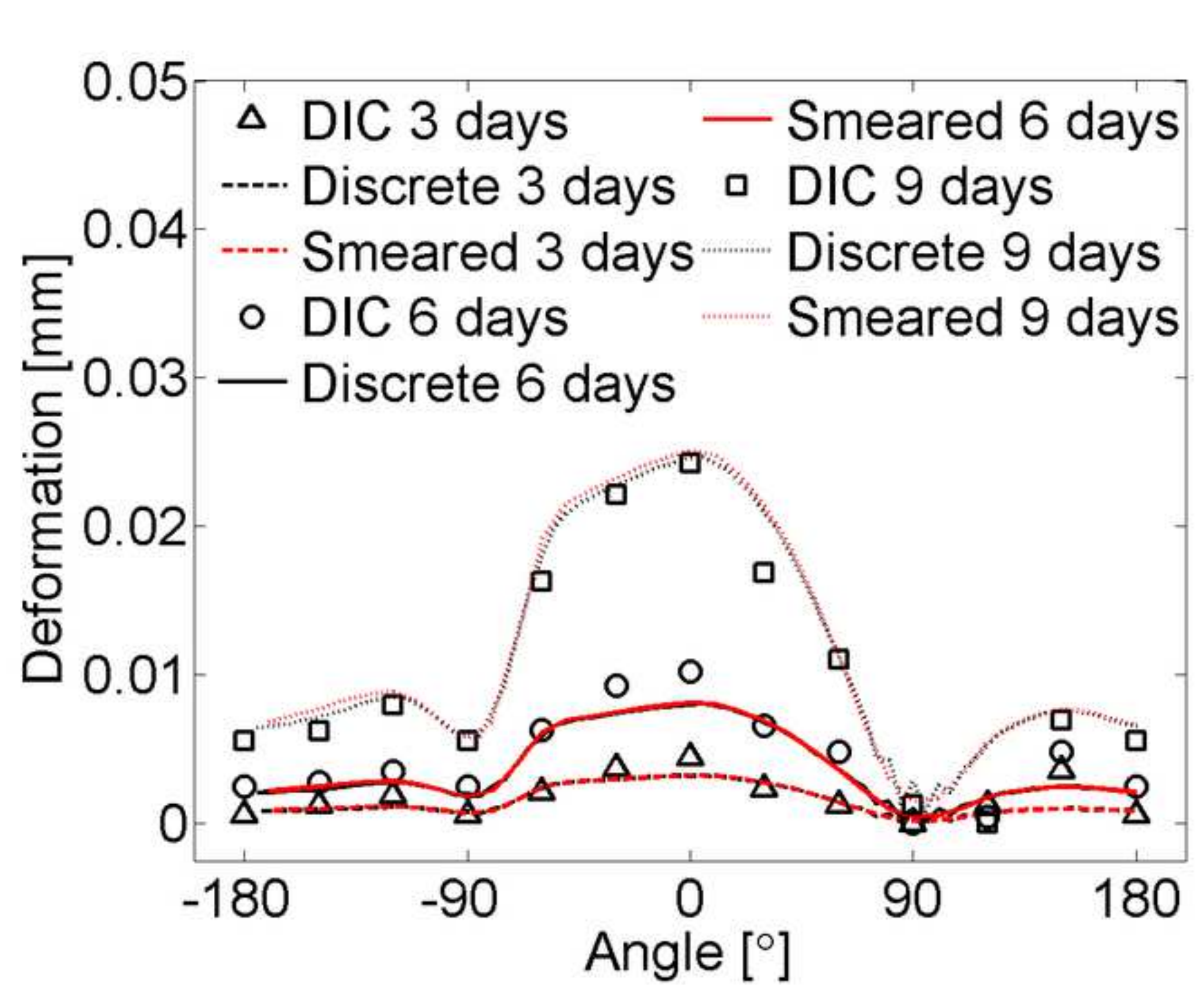




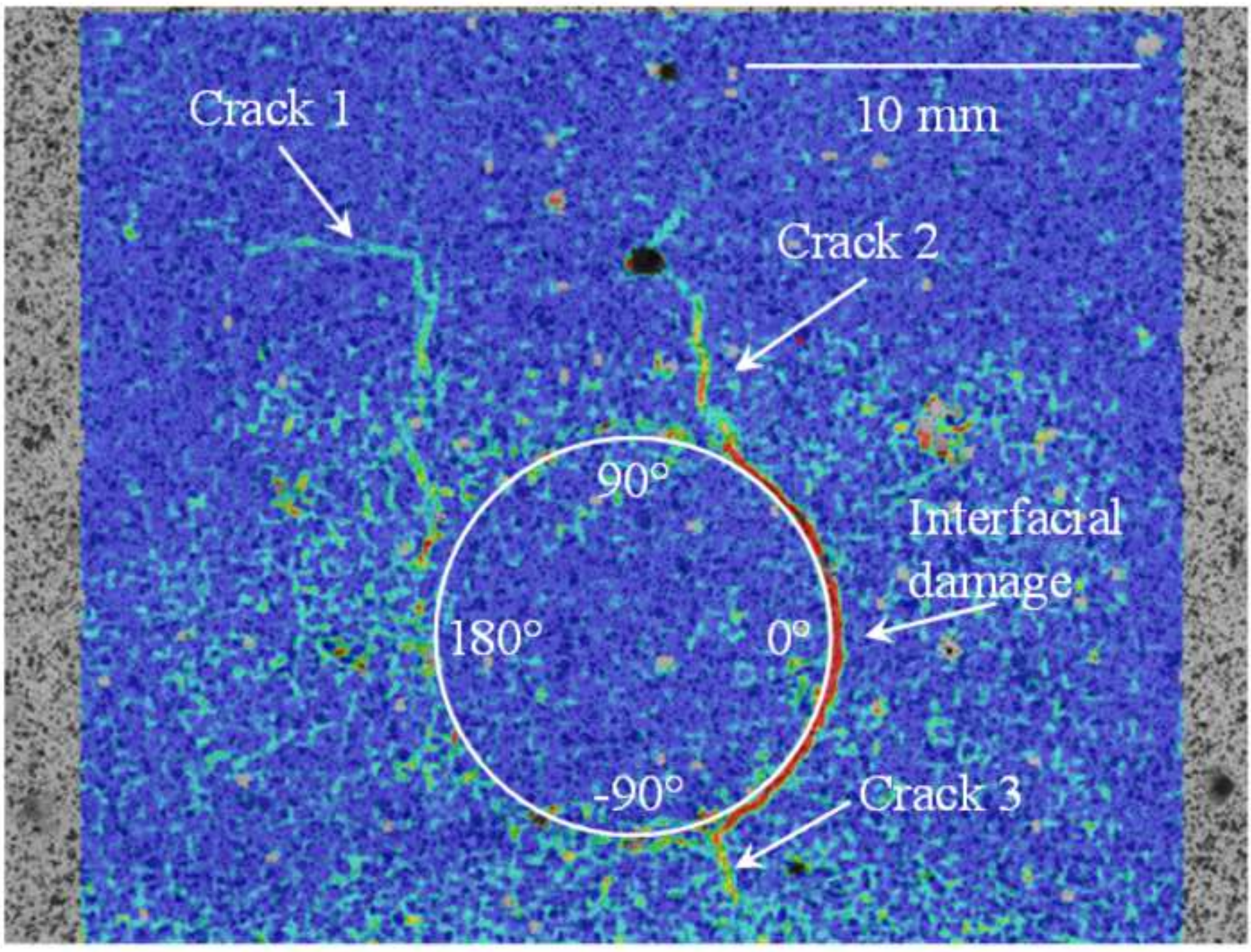




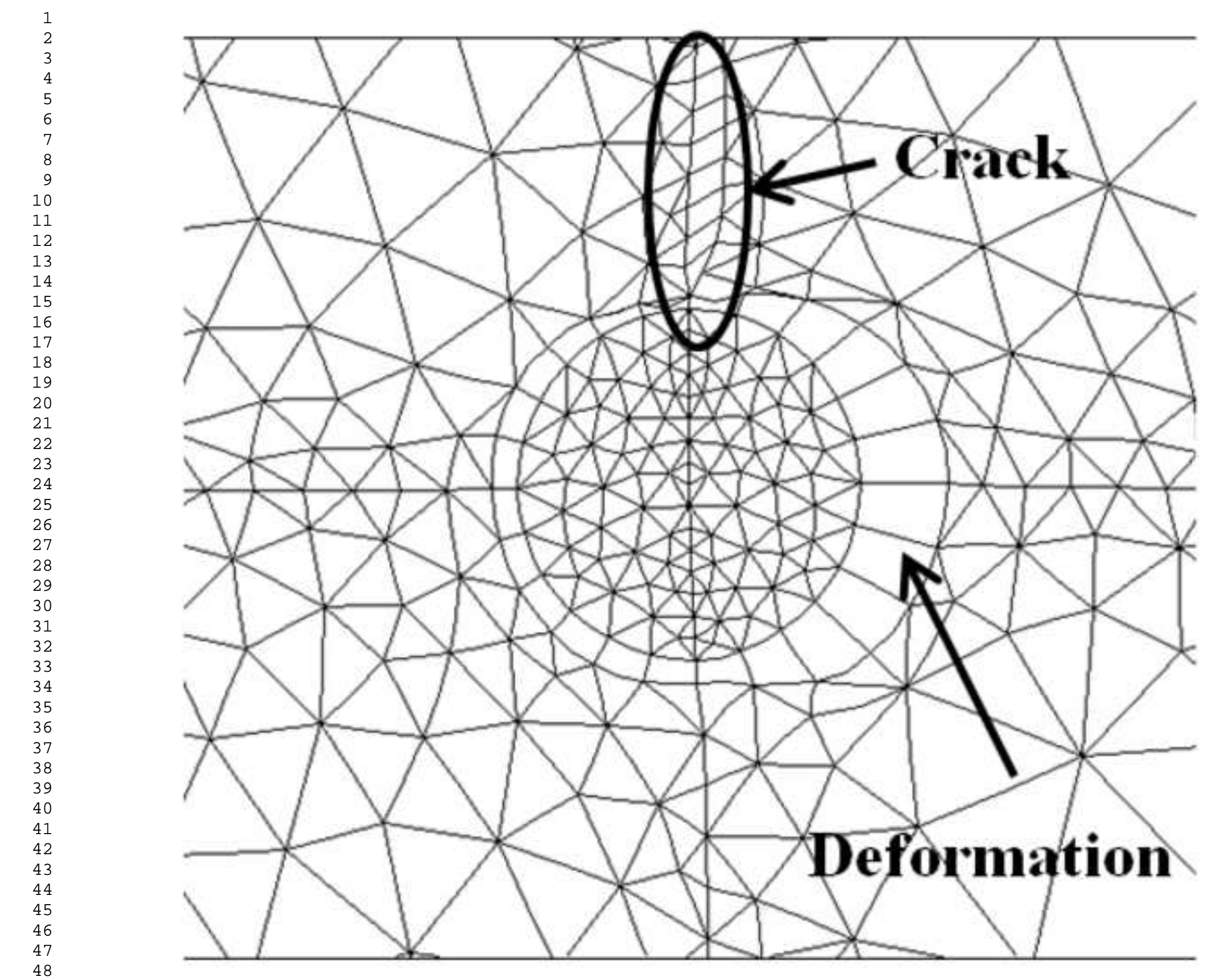




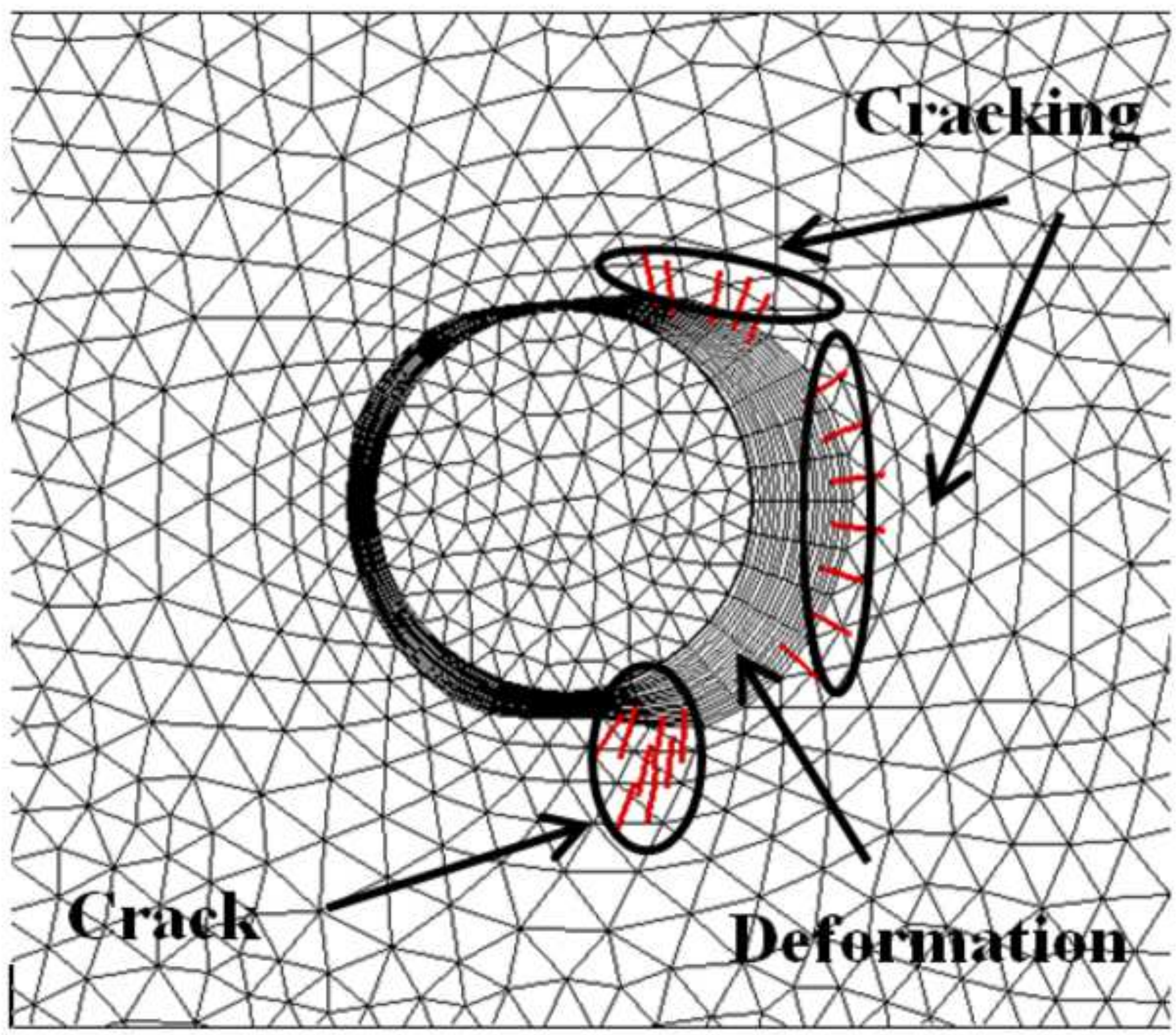




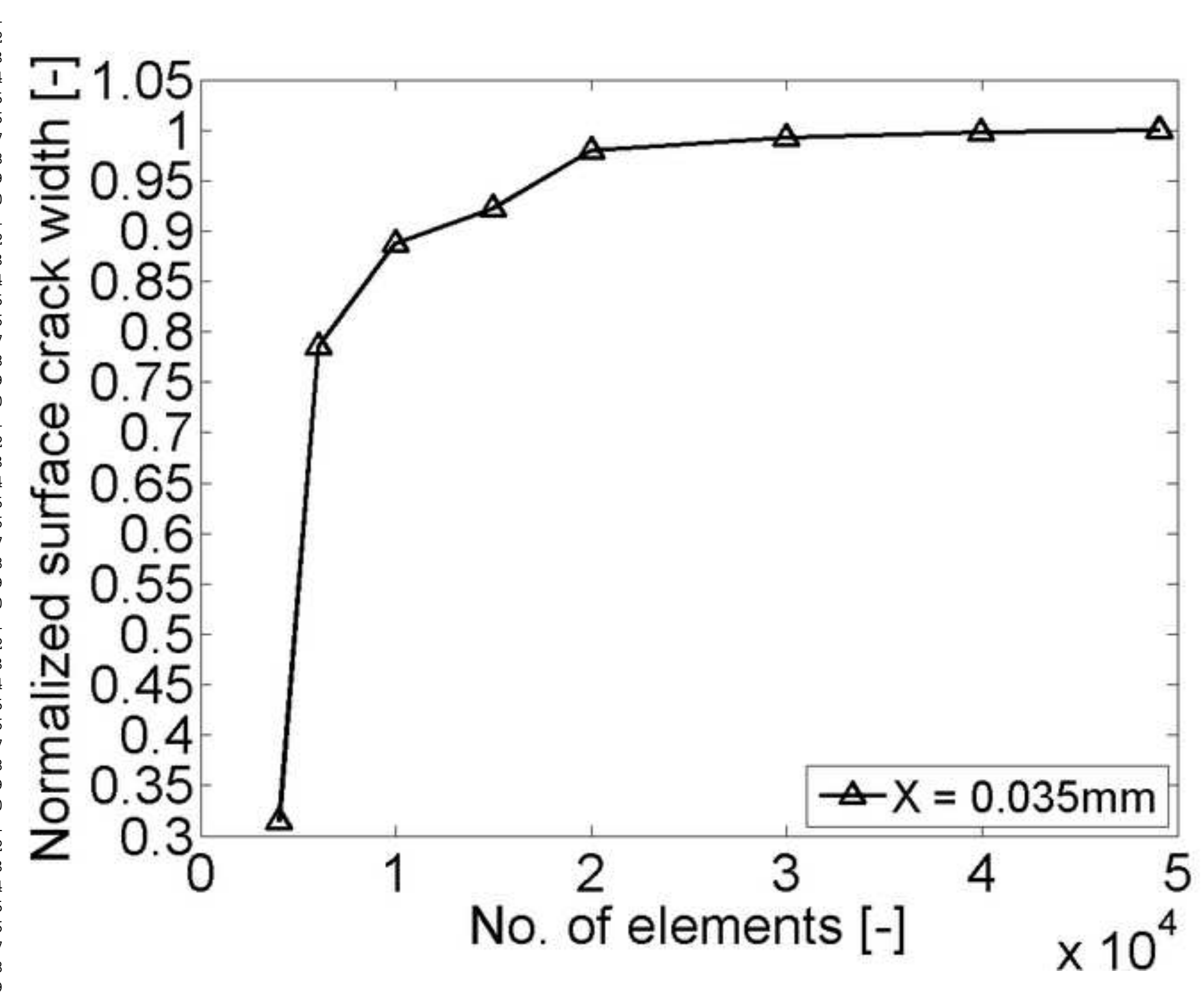




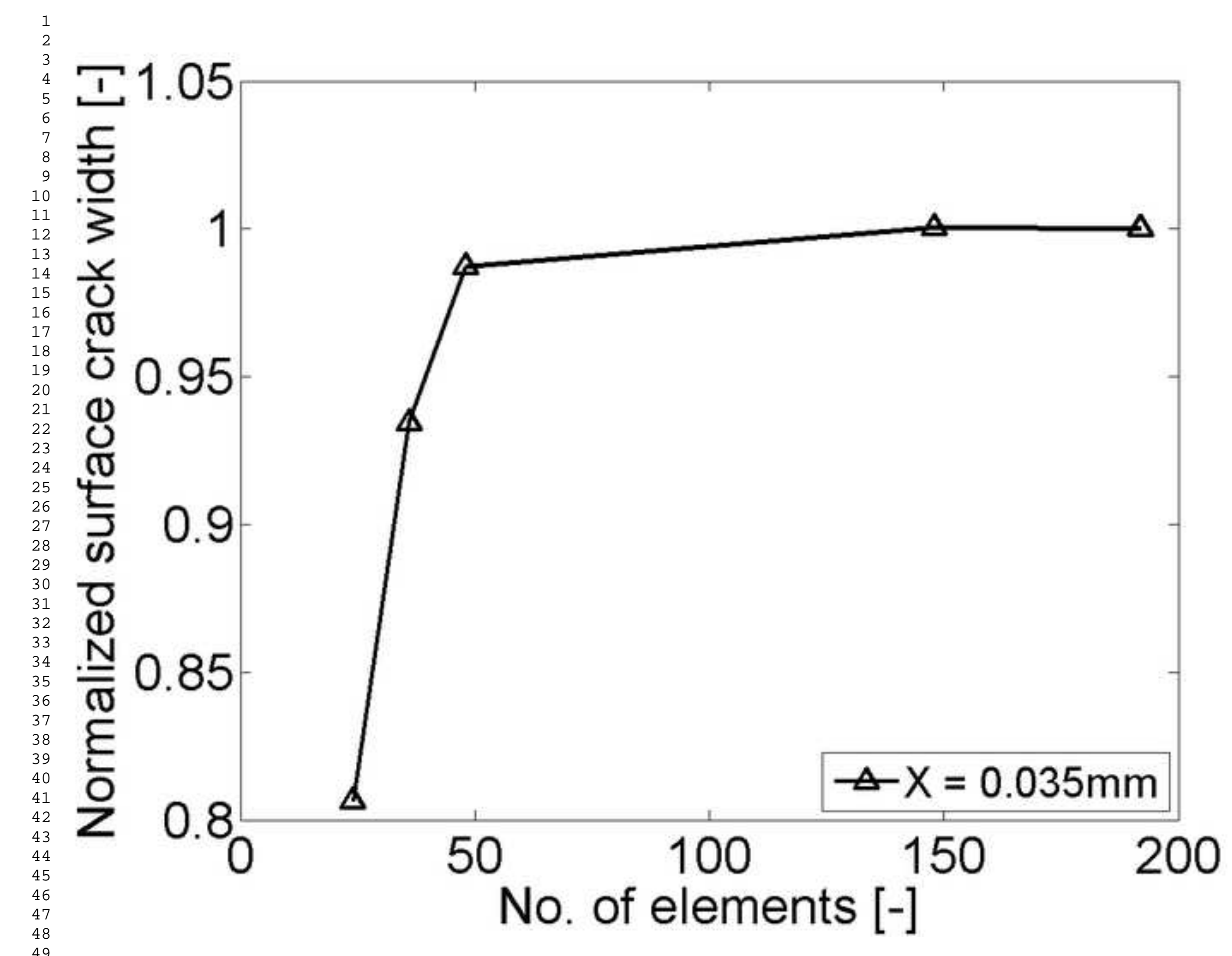




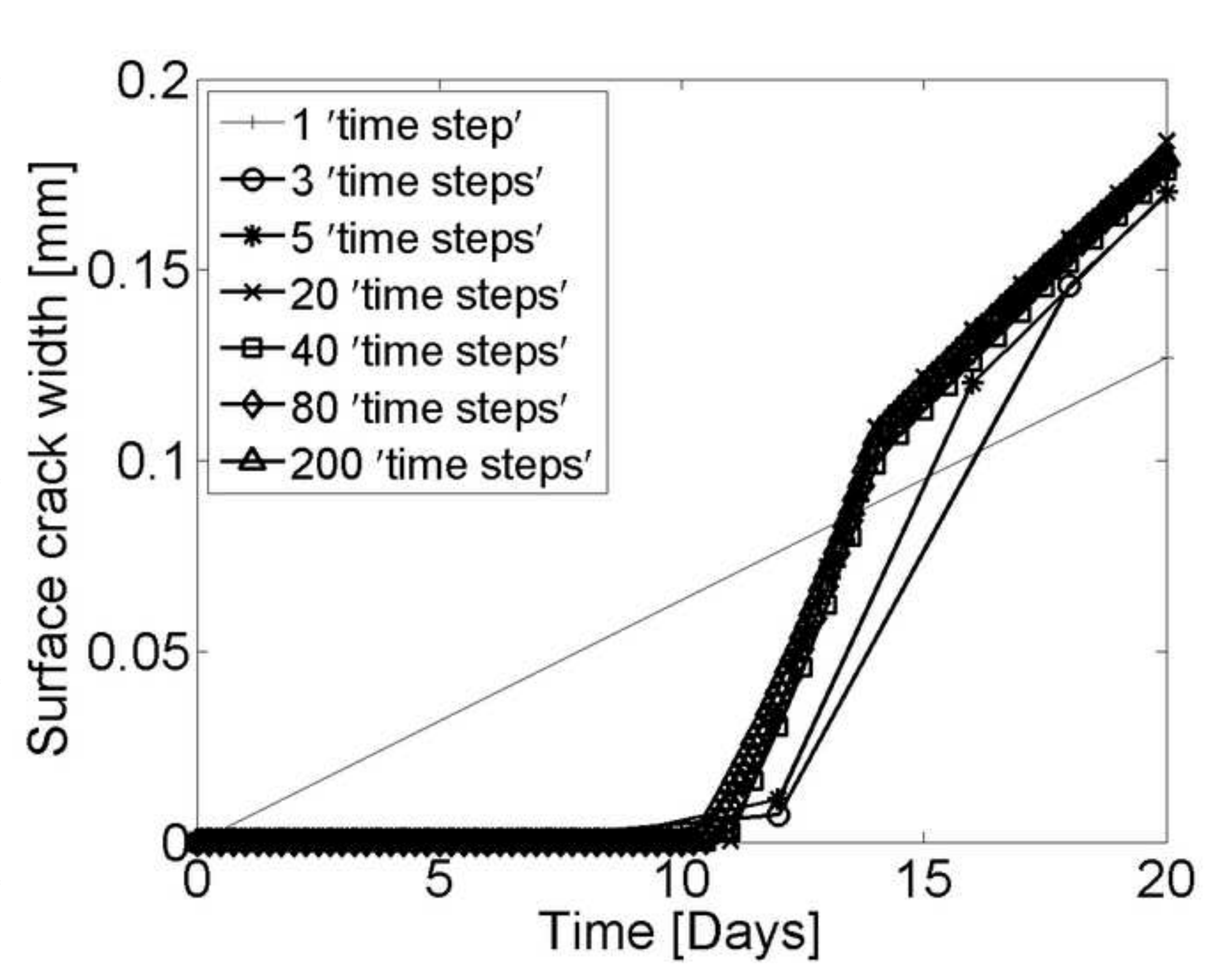




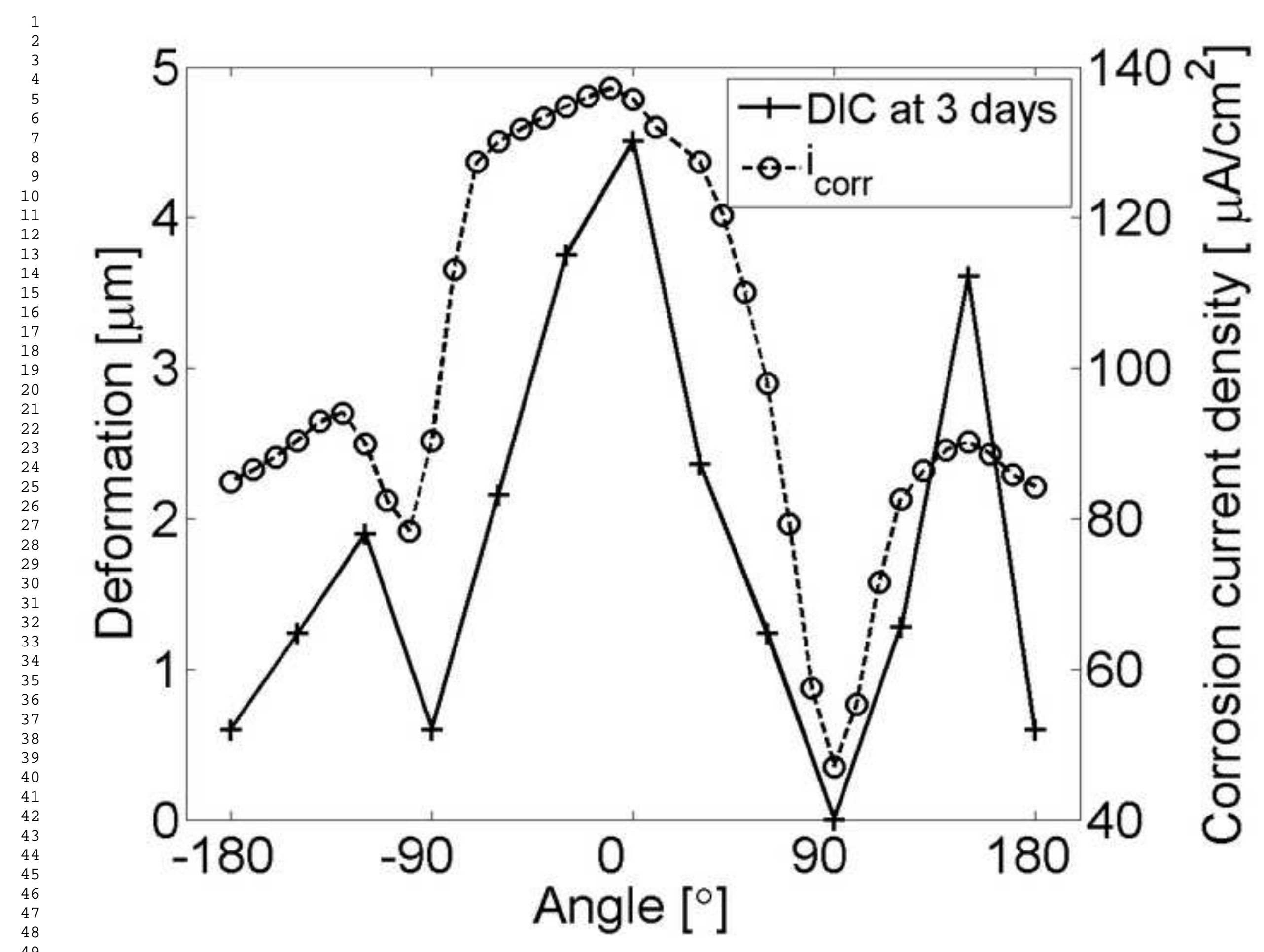




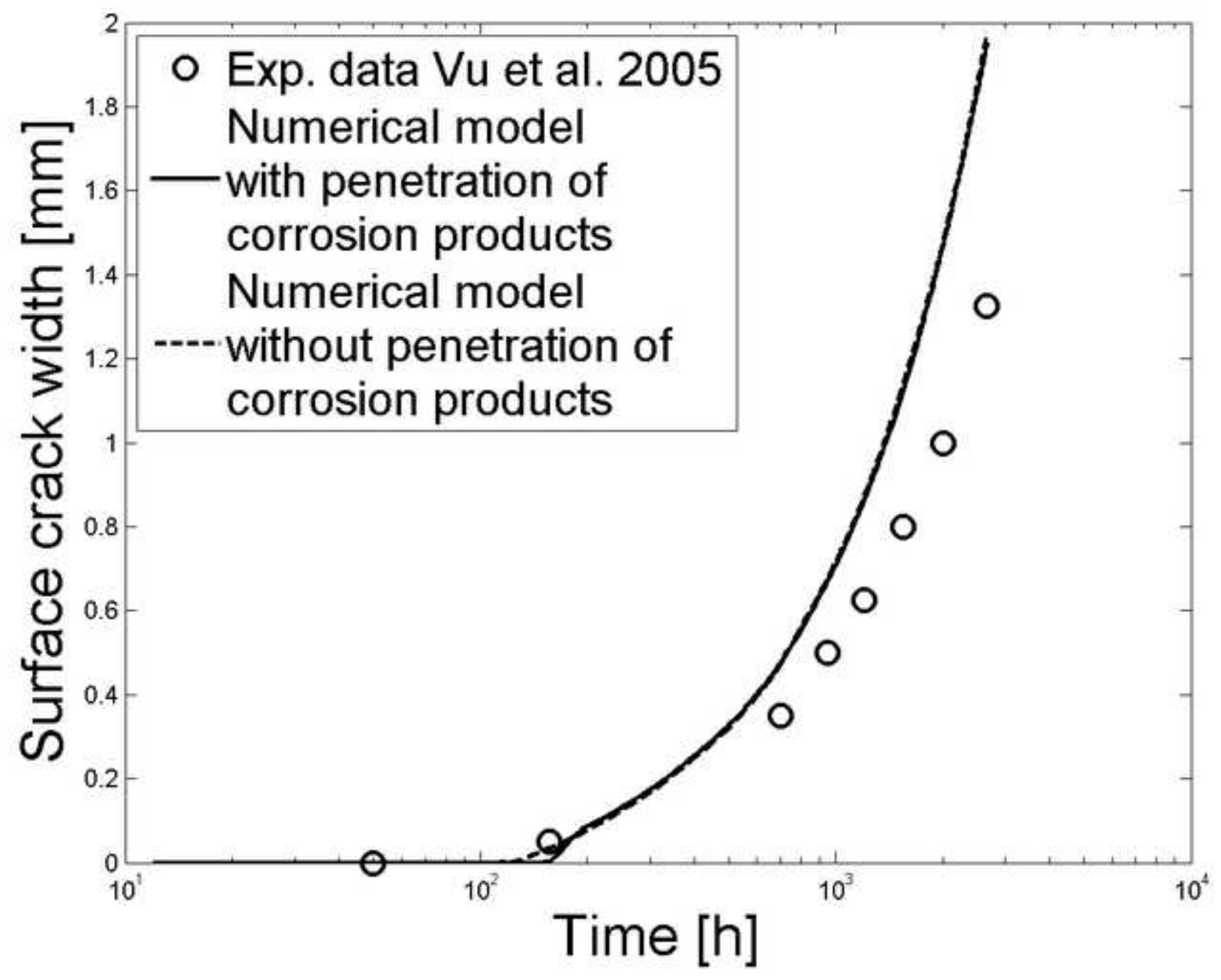




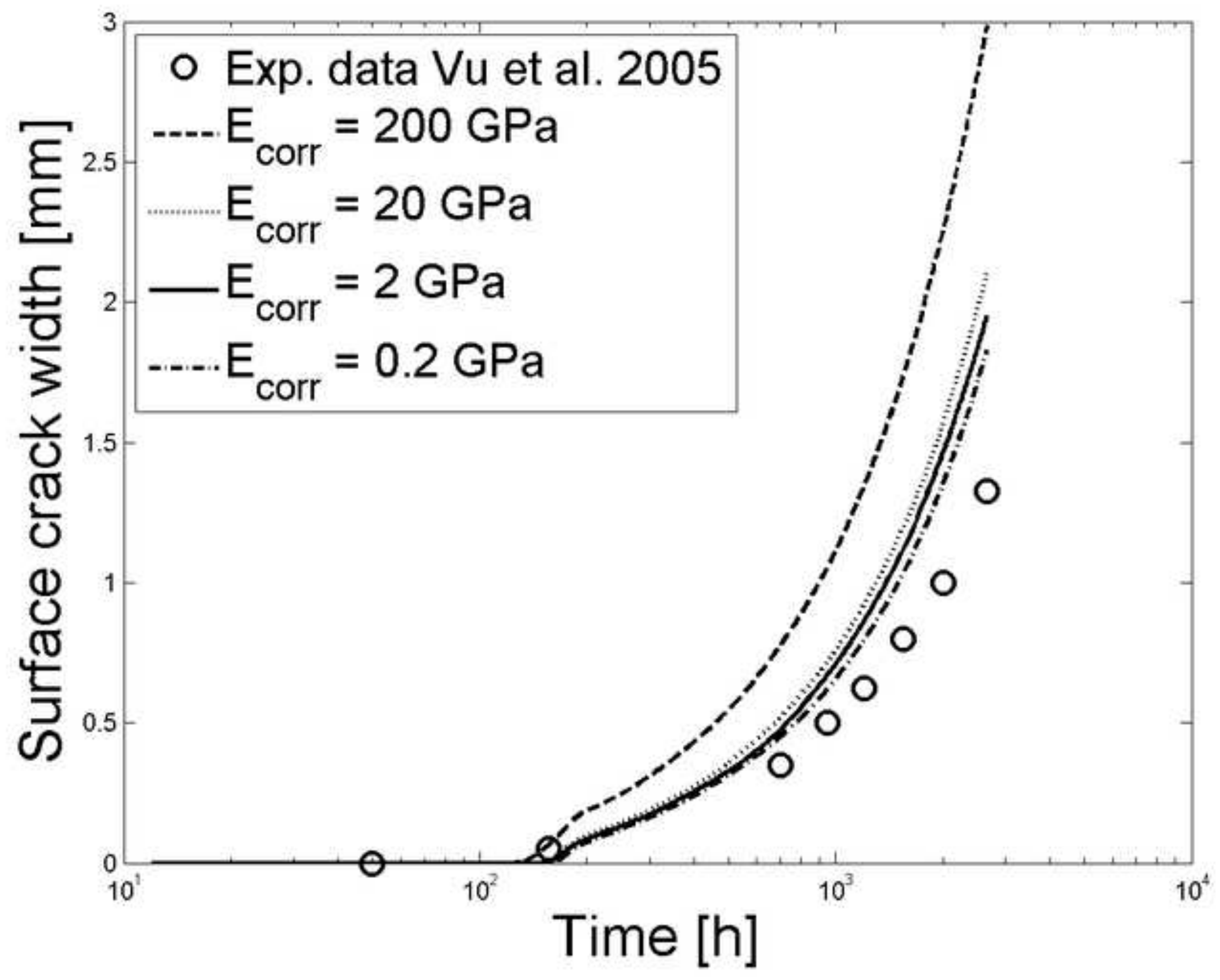

